\title{
Guerra y moneda durante la Independencia del Perú, 1820-1824
}

\author{
por Dionisio de Haro Romero*
}

\begin{abstract}
In the early 1820s, Colonial America is shedding the last vestiges of absolutism by means of the Peruvian independence movement. The Spanish Empire - whose notion of growth is better described as aggrandizement, that is, the result of military and political power that is capable of imposing its laws and orders on its vast overseas regions through the use of force - comes to an end in the war of independence of the Viceroyalty of Peru. As the relation between money and power is fragile in a pre-capitalist system (i.e. without power there is no money and without money there is no power), the mints and the minting of coins during the 1820-1824 campaign became a key element in the region's historical development. This activity does not occur without interesting reform initiatives with the aim to adequately deal with a complex monetary system which is dominated by the urgencies created by the war. The purpose of this paper is to analyze the various initiatives undertaken by the monetary authorities in conflict and the role played by the Peruvian mints during the turbulence of the independence movement.
\end{abstract}

\section{INTRODUCCIÓN}

Desde el siglo XVI España se ha convertido en el proveedor de metales preciosos para los mercados europeos. ${ }^{1}$ Sin embargo, este hecho

* El presente artículo se enmarca dentro del Proyecto de Investigación "Tiempos de desconcierto. Sociedad y Política en la Independencia del Perú, 1820-1824”, Referencia HAR2008-03259, financiado por el Ministerio de Educación y Ciencia, Secretaría de Estado de Universidades e Investigación. Ayudas a proyectos Subprograma Nacional de Investigación Fundamental no orientada. BOE 30-11-2007.

1 Sobre metales preciosos y mercados europeos, vid. Peter Kriedte, Feudalismo tardío y capital mercantil (Barcelona 1994), pp. 47-68; y sobre caudales americanos, vid. John J. TePaske, La Real Hacienda de Nueva España: La Real Caja de México, 1576-1826 (México, D.F. 1988); y Earl J. Hamilton, El Tesoro americano y la Revolución de los precios en España, 1501-1650 (Barcelona 2000). 
no significa que España dispusiera de un sistema monetario moderno o de unas instituciones financieras desarrolladas que permitieran la irrupción del sistema capitalista en la economía española y americana - más bien todo lo contrario. Durante el siglo XVI, y a pesar de la expansión que experimenta el comercio entre la Península y América, España despliega un modelo de conquista netamente feudal ${ }^{2}$ en donde la explotación abierta se convierte en el eje fundamental de la expansión colonial. El fuerte impulso que experimenta el comercio con América en el siglo XVIII, a través de la producción de plata y la liberalización comercial de 1765, sólo tiene efectos muy limitados para la economía peninsular y americana, sin modificar prácticamente su estructura tradicional. ${ }^{3}$ El ciclo de guerras que comienza con la guerra de los Siete Años y que concluye con la guerra de la Independencia significa el fin del sistema colonial español y su desplazamiento por parte del capital francés y británico. De esta forma, los hechos indican que la economía imperial en el circuito monetario europeo no logra apenas retener una cantidad significativa del enorme transvase de riqueza de América a Europa que se produce durante la Edad Moderna. ${ }^{4}$ Por el contrario, los caudales americanos, a través de las instituciones monetarias europeas, son derivados sin interrupción a las plazas comerciales del continente, sin influir lo más mínimo en el potencial proceso de modernización del sistema monetario, insertándose en el proceso de formación del capital europeo. ${ }^{5}$

El sistema tradicional se asienta sobre la base bimetálica o "doble standard" de oro y plata, en el que los dos metales son acuñados libremente en las Casas de la Moneda bajo tarifas de compra establecidas por las autoridades monetarias. Es un sistema bimetálico con base en la plata. ${ }^{6} \mathrm{El}$ oro se acuña en onzas y demás fracciones, y

2 Sobre el modelo de conquista colonial castellana, vid. Pierre Vilar, Crecimiento y desarrollo (Barcelona 1976).

3 Como señala Kriedte, Feudalismo (nota 1), p. 99, la industria española no reunía las condiciones necesarias de competitividad requeridas por el mercado internacional.

4 Vid. Álvaro Espina Montero, "Oro, plata y mercurio, los nervios de la monarquía española”: Revista de Historia Económica XIX, 3 (2001), pp. 507-538

5 A partir del siglo XVI podemos establecer la formación del capital monetario europeo al lograr desprenderse éste de los estrechos lazos que hasta entonces había conservado con el capital comercial, como resultado de un proceso de continua expansión y centralización. Vid. Kriedte, Feudalismo (nota 1), p. 67.

6 Para un análisis más detallado del sistema de acuñación, vid. Felipe Mateu y Llopis, La moneda española. Breve historia monetaria de España (Barcelona 1946), p. 270. 
la plata en duros, reales de a ocho y piezas inferiores. El sistema de acuñaciones se ajusta al modelo del escudo para el oro, el real para la plata y las piezas de cuartos, ochavos y maravedís para el cobre.

La política monetaria se define a través del establecimiento de los pesos y pesas con que se negocia, la fijación de las tarifas de compra de los metales preciosos, el establecimiento de tarifas de cambio con otras monedas extranjeras y los exámenes de afinación y contrastación - todas ellas funciones ejercidas por la institución monetaria dependiente directamente de la Corona, la Real Junta de Comercio, Moneda y Minas, que centraliza la dirección y ejecución de la política monetaria. El sistema de dos áreas relativamente autónomas está caracterizado por la elevada dependencia de la región peninsular con respecto de la americana. ${ }^{7}$ Tanto las Casas de Moneda de la Península, dedicadas a la acuñación de oro y plata, Madrid ${ }^{8}$ y Sevilla, ${ }^{9}$ como las americanas, destacando Ciudad de México ${ }^{10}$ y Lima, ${ }^{11}$ elaboran una moneda de alto valor intrínseco y aplican unos elevados derechos de retención, aunque en estas últimas, las acuñaciones en cospeles tienen una finalización más rústica. La moneda fuerte o bien toma el camino de la exportación, o es retirada de la circulación

7 Guías mineras prácticas para el caso de la Península son: Tomás González Carvajal, Registro de las minas de la Corona de Castilla (Madrid 1832); y Antonio Pérez Domnigo, Memoria sobre las minas en la península (Madrid 1831).

8 Vid., principalmente, Antonio Catalina Adsuard, La antigua ceca de Madrid: una aproximación a su historia (Madrid 1980) y AAVV, Cien años de historia. Fábrica Nacional de Moneda y Timbre (Madrid 1994).

9 Vid. Francisco De Paula Pérez, La Casa de la Moneda de Sevilla: su historia (Sevilla 1992).

${ }^{10}$ Vid., principalmente, para la historia de la Casa de la Moneda de México, Bernardo García Martínez, La Casa de Moneda, siglos XVI-XIX (México, D.F. 1970); y Rafael Dobado/Gustavo A. Marrero, "Minería, crecimiento económico y costes de la independencia de México": Revista de Historia Económica XIX, 3 (2001), pp. 573-611; y Adám Szászdi, "Preliminary Estimates of Gold and Silver Production in America": Hermann Kellenbenz (ed.), Precious Metals in the Age of Expansion: Papers of the XVI th International Congress of the Historial Sciencies (Stuttgart 1981), pp. 151-224, para el estudio detallado de las implicaciones económicas de la producción metálica de plata.

${ }^{11}$ Vid. Humberto F. Burzio, La ceca de Lima (Lima 1958); Carlos Lazo García, Obras escogidas de Carlos Lazo García, tomo III: La moneda (Lima 2008); Manuel Moreyra y Paz Soldán, La moneda colonial en el Perú, capítulos de su historia (Lima 1980); y Eduardo Dargent, Las Casas de Moneda españolas en América del Sur (Lima 2006). 
configurando parte de los tesoros particulares, ${ }^{12}$ siendo así presa de un intenso proceso de tesaurización. ${ }^{13}$ En este sentido, la oferta monetaria peninsular y americana de oro y plata apenas se ve alterada o afectada por la fiebre productora. Por el contrario, se manifiesta una excesiva acuñación de moneda de cobre o de aleación de ínfima calidad, se amplia la circulación de moneda falsificada y se da entrada en el circuito monetario interior a monedas extranjeras muy deterioradas.

La Corona, principal protagonista de este drenaje, dedica las rentas americanas al mantenimiento de la onerosa política militar ${ }^{14}$ y diplomática europea, condenando a la economía imperial a una continua escasez de metales preciosos y a una paupérrima circulación de monedas de oro y plata, agravada de forma progresiva por el persistente déficit crónico en la balanza comercial española. ${ }^{15}$

Las autoridades monetarias, con el aparente fin de hacer frente a la salida de capital sin contraprestación, ${ }^{16}$ se empeñan en una política defensiva de prohibiciones a las exportaciones monetarias con parcos

12 Manuel Lamas, ensayador mayor del reino en 1772, estimó que la moneda circulante en el país en 1772 ascendía a 4.886.229 rs. y que la escondida podía suponer alrededor de la mitad de dicha cifra, esto es, 2.443.000 rs. Vid. José Manuel de Vadillo, Reflexiones sobre la urgencia de remedio a los graves males que hoy se padecen en España por causa de muchas monedas que circulan en ella (Cádiz 1846), p. 51.

${ }_{13}$ Fenómeno estudiado exhaustivamente por Carlos Marx, Contribución a la crítica de la economía política (Madrid 1978), pp. 156-168.

${ }^{14}$ En Richard Ehrenberg, Das Zeitalter der Fugger. Geldkapital und Creditverkehr im 16. Jahrhundert (Jena 1922), puede encontrarse un detallado análisis del recorrido de la plata americana desde los puntos de fabricación hasta los escenarios bélicos. Un estudio detallado del papel de los metales americanos en el sostenimiento de las guerras en la Europa Moderna, vid. Dennos O. Flynn, "El desarrollo del primer capitalismo a pesar de los metales preciosos del Nuevo Mundo: una interpretación anti-wallerstein de la España imperial": Revista de Historia Económica II, 2 (1984), pp. 29-58.

15 Vid. Josep Fontana, La crisis del Antiguo Régimen 1808-1832 (Barcelona 1992), pp. 272-276.

${ }^{16}$ El Banco de San Carlos, desde su constitución, entre sus funciones destaca el encargo de todas las operaciones financieras y monetarias con el exterior, heredando así las competencias del Real Giro. De este modo la única institución capacitada para la exportación de moneda fuera de las fronteras del país es el Banco de San Carlos, y consta que estas operaciones serán de las que mayores beneficios reporte a la entidad tal como explican en sus obras José Canga Argüelles, Diccionario de Hacienda (Madrid 1833); y Pedro Tedde, El banco de San Carlos, 1782-1829 (Madrid 1988). 
resultados. ${ }^{17}$ Las reiteradas disposiciones ${ }^{18}$ sobre permisos, pagos de derechos y guías de circulación se muestran como ineficaces medidas con las que disuadir la masiva exportación de capitales. La contradicción reside en que la exportación de metales se fundamenta en la propia política monetaria tradicional consistente en bajas tarifas de las Casas de Moneda, altos derechos de acuñación y equivalencias oro/ plata en torno a $1 / 16^{\prime} 5$, sensiblemente desfasadas con respecto a Europa, ${ }^{19}$ subvalorando la plata y, por consiguiente, defendiendo en el país las existencias de oro, aunque dicha política empujase a la plata a la exportación a gran escala. La política monetaria tradicional no obedece a principios económicos y monetarios modernos, sino más bien a razones de orden fiscal y defensa de los depósitos tradicionales, considerando el ramo de la acuñación como un instrumento más de su política de ingresos fiscales. ${ }^{20}$ En definitiva, no se tiene como objetivo la consecución de una política monetaria que favoreciese el crecimiento económico. Por el contrario, se mantiene un comportamiento económico feudal cuya lógica comprende la maximización en el cobro de rentas y no se concibe al sistema monetario como un instrumento clave en una economía de mercado en desarrollo. Es decir, preserva un sistema monetario incapaz de impulsar el crecimiento económico peninsular y americano a través de una oferta monetaria que proporcione la liquidez suficiente con la que cubrir los tráficos y garantizar las inversiones.

En otro orden de cosas, la política monetaria de moneda fuerte viene también determinada por la propia debilidad de la economía española y la falta absoluta de confianza por parte de los agentes económicos hacia las autoridades monetarias, y a quienes representaba. Los procesos de envilecimiento de la moneda ejecutados por la Corona de forma abusiva durante todo el siglo XVII, las sucesivas bancarrotas de los Austrias menores, las fracasadas operaciones de los

17 Archivo General de Simancas, Dirección General de Rentas, Extracción de moneda 1564-1806, legajos 4880-4942.

${ }_{18}$ Medidas todas ellas que permanecieron en vigor anacrónicamente hasta el Decreto de 14 de agosto de 1839, aunque durante el Trienio Constitucional se debatiese sin éxito la libertad total de circulación de moneda.

${ }^{19}$ En Gran Bretaña esta equivalencia correspondía a 1/15`2 y en Francia en torno al $1 / 15^{\prime} 4$.

${ }^{20}$ Vid. J. Sardá Dexeus, La política monetaria y las fluctuaciones de la economía española en el siglo XIX (Barcelona 1998), p. 19. 
vales reales a finales del siglo XVIII, las abultadas emisiones de moneda de cobre y la ausencia de instituciones financieras y bancarias modernas en el país, entorpecen el posible desarrollo de un sistema monetario moderno y la implantación en nuestra economía del dinero signo o muestra, ${ }^{21}$ cuya consolidación sólo está garantizada por el consentimiento general del público y un cierto nivel de reservas. ${ }^{22}$

En definitiva, la política monetaria tradicional, lejos de favorecer la modernización del imperio, ${ }^{23}$ se convertirá en un serio obstáculo al mantener una oferta monetaria muy restrictiva. A la política monetaria tradicional hay que unir la escasa implantación de instituciones financieras y bancarias en cuanto a su número y variedad, constituyendo su carencia un serio obstáculo para el crecimiento y desarrollo tanto de la economía peninsular como de la americana. ${ }^{24}$

\section{Las Casas de la Moneda peruanas durante LA GUERRA DE INDEPENDENCIA (1820-1824): Máquinas SIN PLATA Y PLATA SIN MÁQUiNAS}

Para estudiar la historia monetaria peruana durante la guerra de la Independencia vamos a centrar el análisis, por una parte, en el caso de la Casa de la Moneda de Lima, principal instrumento monetario con el que cuenta el bando patriótico durante el periodo del Protectorado y, por otra, en la experiencia de la Casa de la Moneda de Cuzco, a su vez institución clave con la que se manejará el bando realista ya en la fase última de la guerra.

Antes de entrar en la historia monetaria peruana durante la guerra de Independencia es necesario plantear alguna consideración de cómo se había desarrollado el problema monetario en décadas anteriores. En

21 Acerca de la moneda como signo de valor desde el concepto dinero mercancía hasta moneda crédito, vid. Marx, Contribución (nota 13), pp. 137-153.

${ }^{22}$ Sobre la confianza del mercado como base de los sistemas monetarios modernos, puede verse David Ricardo, Obras y correspondencia, vol. 6: Cartas 1815-1818, Piero Sraffa (ed.) (México, D.F. 1962).

${ }^{23}$ Para Sardá, La política monetaria (nota 20), p. 21, este problema mantiene las iniciativas capitalistas "aherrojadas".

${ }^{24}$ Rondo Cameron, La banca en las primeras etapas de la industrialización (Madrid 1974), pp. 17-19, explica la importancia estratégica que desempeñan las instituciones financieras en el desarrollo. 
este sentido, se puede indicar que todas las controversias monetarias ya expuestas en la introducción - en cuanto a los efectos perversos de una política monetaria tradicional sustentada sobre un sistema que impulsa al numerario, de forma natural, hacia la exportación y el atesoramiento - están también presentes en la economía del Virreinato del Perú, acaso de forma más acentuada. Asimismo, la política de prohibiciones y rígidas normas de circulación de numerario metálico apenas llegó a impedir el intenso tráfico ilegal que, junto a la fuerte corriente exportadora oficial, acabó por prácticamente "secar" los circuitos monetarios internos peruanos, siendo habitual en numerosas transacciones mercantiles la práctica del intercambio real o la utilización de algún signo de representación primitivo como es el caso de ajíes, cacao u otros similares. De esta forma, el Virreinato se movía de forma esquizofrénica entre la deflación por escasez de numerario y la inflación debido a la difusión de dinero de ínfima calidad, como así ocurrió con la experiencia de los vales emitidos en la época de gobierno de Fernando de Abascal en 1815. La política monetaria española, al igual que con respecto a la Península, no estuvo a la altura de las demandas requeridas por la economía del Virreinato, fundamentalmente por la presiones ineludibles de la Real Hacienda, convirtiéndose ésta en el principal obstáculo para un adecuado desarrollo monetario más acorde con las nuevas corrientes de crecimiento económico.

Con la expedición libertadora del Perú, dirigida por el general José de San Martín, y su desembarco en la Bahía de Pisco en septiembre de 1820, el Perú inició un largo ciclo de guerras en el que el dinero y las necesidades de financiación por parte de los bandos enfrentados adquiriría una máxima dimensión, obligando a las partes enfrentadas a explorar iniciativas monetarias novedosas con las que sortear respectivamente la paradoja de máquinas sin plata y plata sin máquinas, lo que les permita mantener el nervio durante la larga campaña militar: Nervus belli, pecunia. El norte y la franja costera, incluida la ciudad de Lima en la que se proclamó la independencia el día 28 de julio de 1821, queda bajo el control patriota; mientras que el sur y el centro del país, tomando como nueva capital la ciudad de Cuzco, se mantiene bajo a egida realista. Desde la perspectiva monetaria, Lima dispone del instrumento con el que crear dinero al tener a su disposición la infraestructura de la Casa de Moneda, aunque inmediatamente chocará con el obstáculo de la falta de materia prima. Cuzco, por el con- 
trario, dispone de los principales yacimientos y explotaciones de metales preciosos de la cordillera, incluyendo cerro Pasco, pero es incapaz de transformar las pastas en numerario efectivo ante la falta de los ingenios precisos.

\section{La Casa de la Moneda de Lima y la Política MONETARIA DEL PROTECTORADO}

Desde el comienzo de la guerra de Independencia, la compleja situación monetaria se deterioró muy rápidamente. El principal problema monetario con el que se vio enfrentada la economía peruana ya desde comienzos del siglo XIX es la extraordinaria escasez de numerario, que se agravó a comienzos de 1821 de manera extrema. La Ceca de Lima, principal institución monetaria del sistema colonial español en el Perú, había transitado durante el pasado lustro con más sombras que luces. La Casa de la Moneda había quedado muy rezagada tecnológicamente, ${ }^{25}$ obligando a mantener unos altos derechos de retención, motivados por la razón fiscal y los costes de producción. Con respecto a la acuñación, valorada en torno a unos cinco millones y medio de pesos anuales, prácticamente en su totalidad o bien toma el camino de la exportación, o es presa del proceso de tesaurización. Por una parte, únicamente el numerario chileno desde 1817, como en parte ya ocurría en la Península con la moneda francesa desde la guerra de Independencia, viene a paliar parcialmente el pobre volumen de circulante interior, acabando por ser legal su curso a partir de agosto de 1821. Y por otra, la escasez de numerario es tan rigurosa que incluso acaba por afectar al comercio minorista limeño, dándose el curioso caso de la creación de las fichas de pulpero, piezas de plomo $\mathrm{u}$ otro material, emitidas por colmados, pulperías y bodegas con el objeto de poder realizar compras que a futuro se hiciesen en el mismo establecimiento que las entregaba como cambio. Estas fichas, generalmente de un cuartillo, acaban siendo aceptadas como pago por otros comerciantes y el público en general. Las pulperías consolidan, ante la falta de respuesta oficial, una curiosa red monetaria, a modo de free

25 A pesar de algunas iniciativas interesantes como son las de Richard Trevithick en 1817, con relación a la adopción de la energía hidráulica en los procesos de acuñación en la Casa de la Moneda de Lima. Vid. Dargent, Las Casas de Moneda (nota 11). 
banking, actuando como entidades emisoras en el estrato inferior de la circulación monetaria y logrando la confianza por parte del público sobre la base de un cierto nivel de capitalización y un autorregulado sistema de emisiones. El modelo aún resistirá y competirá eficazmente a los cuartillos emitidos por San Martín en la fase del Protectorado. ${ }^{26}$

Con todo, en el primer semestre de 1821, la acuñación de plata por parte de la Casa de la Moneda de Lima se reduce a una cuarta parte si lo comparamos con los datos correspondientes al ejercicio de 1820 . Tras la proclamación de la independencia en julio de 1821 por parte de San Martín en la Plaza de Armas de la ciudad de Lima, el Gobierno tiene que reconstruir su nervio para la guerra en un contexto muy desfavorable con una Casa de la Moneda previamente descapitalizada por las fuerzas realistas, una circulación monetaria casi simbólica, un crédito interior agotado por la ya larga crisis de la economía peruana y el fiasco del empréstito del virrey Fernando de Abascal de abril de 1815 y unas minas de metales preciosos que permanecen en poder de los seguidores de La Serna.

Las medidas monetarias previas adoptadas por el Gobierno tienen que ver con el bloqueo monetario y financiero con el objetivo de frenar la extracción de numerario y fondos, y con la inyección de un fondo extraordinario a la Casa de la Moneda con el objeto de volverla a poner en funcionamiento ordinario. Así se recoge en las órdenes cursadas por el Gobierno el 9 y 10 de agosto de 1821.

Sin embargo, dichas disposiciones tienen, con respecto a la primera, una nula incidencia práctica, y en cuanto a la segunda un efecto muy limitado debido a la escasa llevanza de pastas a la Casa de la Moneda y la nefasta gestión del envío de sus fondos por motivos de seguridad al puerto de Ancón ${ }^{27}$ que obligan, como así recoge la siguiente cita, a disponer de medidas extraordinarias con las que mantener una mínima actividad en la ceca:

"Ministerio de Hacienda - Por la razón que sigue de lo acuñado en la casa de moneda, desde el 20 de octubre último hasta el 26 de Noviembre, se ve la actividad con que se ha trabajado, y que habría sido mayor el producto si la casa no hubiera sufrido el detrimento de perder todos sus fondos en Ancon como se ha dicho en la

${ }^{26}$ Decreto de 18 de febrero de 1822, "Monedas de cobre de valor de un cuarto y un octavo de peso": Comisión Nacional del Sesquicentenario de la Independencia del Perú (ed.), Colección Documental de la Independencia del Perú, tomo XIII: Obra de gobierno y epistolario de San Martín (Lima 1971), p. 102.

27 Ibidem, pp. 125-128. 
gaceta número 31. Con más numerario habría hecho mayor número de compras de marcos de chafalonía en el banco de rescate, y circulado más cantidad de barras y piñas pagándolas prontamente, la amonedación habría por consiguiente aumentado. Bajo estas consideraciones el Excmo. Sr. Protector del Perú, después de haber oído el dictamen del director de la casa de moneda, ha resuelto que se puedan tomar algunos capitales hasta que completen la suma de cien mil pesos al seis por ciento de interés, pagaderos de seis meses en adelante, en todo, ó en partes como estipulasen los interesado, para que circule con más brevedad el giro en la referida casa, y perciba el público las ventajas que deben $\operatorname{resultar}^{28}$

Llegados a este punto de inflexión, los esfuerzos militares requieren la exploración de nuevos experimentos con los que obtener la liquidez requerida ante el bloqueo o agotamiento de las vías tradicionales. $\mathrm{La}$ iniciativa novedosa por la que se optó con el doble objetivo de, por un lado, poder lograr los fondos monetarios precisos con los que mantener el esfuerzo público en la guerra y, por otro, lograr un mínimo de liquidez con la que sostener la precaria actividad económica interior fue la de crear en octubre de 1821 un Banco Emisor, el "Banco Auxiliar de Papel Moneda". ${ }^{29}$

"El modelo de sistema fiduciario es ideado por una comisión especial conformada por: Andrés Salazar, Pedro Abadía, Matías Maestro, Diego Aliaga y Antonio Álvarez de Villar. Dicha comisión toma como modelo los sistemas de crédito europeos, y en especial el caso británico, para esbozar su propuesta de papel moneda peruana con la que alcanzar la suficiencia fiscal e impulsar la actividad económica general. A pesar de las numerosas citas de autores clásicos en su exposición de motivos hay una clara referencia teórica en el modelo finalmente esbozado: Ensayo Económico sobre el sistema de la moneda-papel: y sobre el crédito público, de José Alonso Ortiz y publicada en Madrid en la imprenta real en 1796. La clave de arco del sistema se sustenta en la confianza del mercado y para ello en el escrupuloso cumplimiento de los compromisos de redención desde la esfera pública. Se nombra como director y tesorero-contador, respectivamente, a los señores Salazar y Alvares Villar. El plan arranca con una garantía de un millón de pesos obtenidos a partes iguales por el estado, a través de la reforma de la caja de censos y de aportaciones particulares procedentes de comerciantes y propietarios. El Banco gira papel moneda a partir del 1 de febrero de

${ }^{28}$ Ibidem, p. 85.

${ }^{29}$ Ley de 14 de diciembre de 1822: Gaceta del Gobierno de Lima Independiente, 9 de enero de 1823 . 
1822 con billetes de 8 reales, 10 y 50 pesos. El compromiso descansa sobre el saldo por parte del estado de las obligaciones asumidas en plazo, mitad en metálico y mitad en papel con la emisión de los respectivos vales de 100 y 500 pesos, respetando escrupulosamente la lógica planteada en el siguiente cuadro de redención: "Idea de un Banco auxiliar: dispuesto en primer lugar con el objeto de que el ingreso anual de las rentas en dinero se duplique, creando igual cantidad en billetes para hacer pagamentos: en segundo, para rescatar y amortizar aquellos billetes con mitad en metálico y mitad en vales de premio, a saber: ${ }^{30}$

\begin{tabular}{l|r|r}
\hline $\begin{array}{l}\text { Fondos para pagamentos a razón de } \\
\text { 200 mil pesos mensuales, mitad en billetes, } \\
\text { y mitad en dinero }\end{array}$ & $\begin{array}{c}\text { Creación anual } \\
\text { en billetes y } \\
\text { vales, pesos }\end{array}$ & $\begin{array}{c}\text { Acopio en } \\
\text { dinero durante } \\
\text { el año, pesos }\end{array}$ \\
\hline $\begin{array}{l}400.000 \text { billetes de á 8 reales para pagar } \\
\text { cantidades menores }\end{array}$ & 400.000 & 400.000 \\
\hline $\begin{array}{l}40.000 \text { billetes de á 10 pesos para cantidades } \\
\text { mayores }\end{array}$ & 400.000 & 400.000 \\
\hline $\begin{array}{l}8.000 \text { billetes de á } 50 \text { pesos para id. Y reducir á } \\
\text { estos los anteriores }\end{array}$ & 400.000 & 400.000 \\
\hline $\begin{array}{l}\text { Fondo primitivo en billetes. Fondo primitivo en } \\
\text { dinero }\end{array}$ & 1.200 .000 & 1.200 .000 \\
\hline $\begin{array}{l}\text { Se crearán 6.000 vales de á 100 pesos, que } \\
\text { ganarán el 4 por 100; y con igual cantidad en } \\
\text { dinero se amortizará la mitad de los billetes }\end{array}$ & 600.000 & 600.000 \\
\hline $\begin{array}{l}\text { Se crearán } 600 \text { vales de á } 500 \text { pesos, que ganarán } \\
\text { el } 5 \text { por } 100 ; \text { y con igual cantidad de dinero se } \\
\text { amortizará la mitad de los vales anteriores }\end{array}$ & & 300.000 \\
\hline
\end{tabular}

\begin{tabular}{l|c|r}
\hline $\begin{array}{l}\text { Fondo para rescatar los billetes anteriores } \\
\text { creando vales de premio, y amortizando la } \\
\text { mitad con dinero }\end{array}$ & $\begin{array}{c}\text { Creación anual } \\
\text { en billetes y } \\
\text { vales, pesos }\end{array}$ & $\begin{array}{c}\text { Acopio en } \\
\text { dinero durante } \\
\text { el año pesos }\end{array}$ \\
\hline $\begin{array}{l}\text { Se crearán 150 pólizas ó vales de á 1.000 pesos, } \\
\text { que ganarán el 6 por 100; y con igual cantidad } \\
\text { en dinero se amortizará la mitad de los vales } \\
\text { anteriores }\end{array}$ & 150.000 & 150.000 \\
\hline $\begin{array}{l}\text { En } 30 \text { de diciembre se entregarán en dinero para } \\
\text { amortizar dichas pólizas }\end{array}$ & 150.000 & \\
\hline \begin{tabular}{l} 
Total fondo en papel, Total fondo en dinero \\
\hline
\end{tabular} & 2.250 .000 & 2.400 .000 \\
\hline
\end{tabular}

${ }^{30}$ Colección Documental de la Independencia, (nota 26), p. 255. 
El proyecto supondrá un sostén estratégico para la administración del Protectorado. Según los datos que nos ofrece la Tesorería General del Estado, el Banco Auxiliar, durante su corto recorrido como emisor, realiza aportaciones mensuales regulares a la Hacienda de San Martín que oscilan entre los máximos de 90.000 pesos del mes de mayo de 1822 y 20.000 pesos del mes de marzo, alcanzando un volumen total de 360.000 pesos antes de la extinción del modelo en el mes de septiembre de 1822.

\section{GrÁFICO 1: RELACIÓN INGRESOS/APORTACIÓN DEL BANCO AUXILIAR}

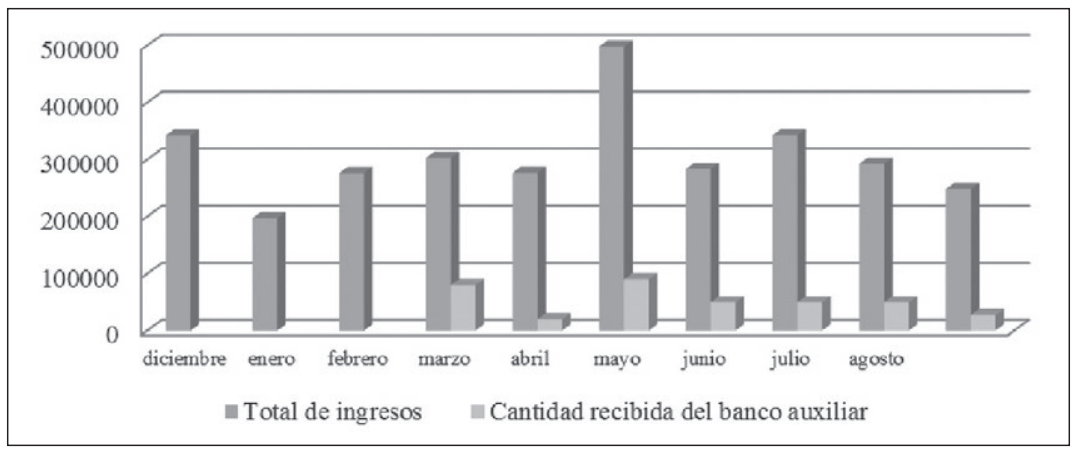

Fuente: Colección documental de la Independencia del Perú (nota 26), pp. 121-232.

Sin embargo, las condiciones objetivas de la economía peruana no permitían la mínima solvencia demandada por un proyecto tan ambicioso. Las razones fiscales conducen a un modelo imposible de gestionar en la práctica, fundamentalmente por dos razones: primero, el extraordinario volumen de papel-moneda, puesto en un mercado tan frágil; y segundo, la imposibilidad de lograr un mínimo de reservas metálicas en la esfera pública - condición necesaria - con las que sostener el impulso fiduciario. Los reiterados anuncios de cumplimiento por parte del banco de los trimestres de vencimiento ${ }^{31}$ son claramente insuficientes cuando, por otra parte, la Casa de la Moneda permanece inerme en su función vital de surtir de un mínimo de metálico al mercado y al propio Estado. El metálico con el cuño "Perú Libre", aprobado mediante el decreto siguiente, tendría como función central el sostenimiento del impulso fiduciario:

\footnotetext{
31 Ibidem, pp. 106-107.
} 
"He acordado y decreto:

$1^{\circ}$. La nueva moneda del Perú se pondrá en circulación desde el día de mañana, y será recibida por el mismo valor que la antigua, por ser de la misma ley y peso que hasta aquí ha tenido.

$2^{\circ}$. La nueva moneda del Perú, se distinguirá por las armas provisionales del estado, que lleva en el anverso con esta inscripción, Perú libera, y en el reverso, la justicia y la paz, con una columna en el centro, y la inscripción que dice, Por la virtud y la justicia. $3^{\circ}$. Los que rehusaren recibir esta moneda, incurrirán en las penas establecidas por la ley. $4^{\circ}$. El ministro de relaciones exteriores avisará oficialmente a los gobiernos amigos y aliados, lo prevenido en el artículo $1^{\circ}$ de este decreto, remitiéndoles las monedas del nuevo cuño para su conocimiento. Comuníquese al director de la casa de moneda, publíquese por bando, e insértese en la gaceta oficial. Dado en el palacio del supremo gobierno, en Lima a 15 de julio de 1822.- $3^{\circ}$.- Firmado.- Trujillo.- Por orden de S.E.- B. Monetagudo".32

Sin embargo, la presencia de estas monedas en el circuito monetario limeño es puramente anecdótica y todo un modelo sustentado en la hipótesis de una rápida recuperación militar de los yacimientos de oro y plata del interior, comienza a naufragar de forma acelerada, ayudado por la falsificación masiva de billetes de baja y media representación. La Dirección del Banco Auxiliar hará ímprobos esfuerzos para hacer frente a este problema, entre otros burilando nuevas ediciones, ${ }^{33}$ con escasos efectos reales sobre tal fraude.

Gráfico 2: Relación de entregas: Casa de la Moneda/Banco Auxiliar

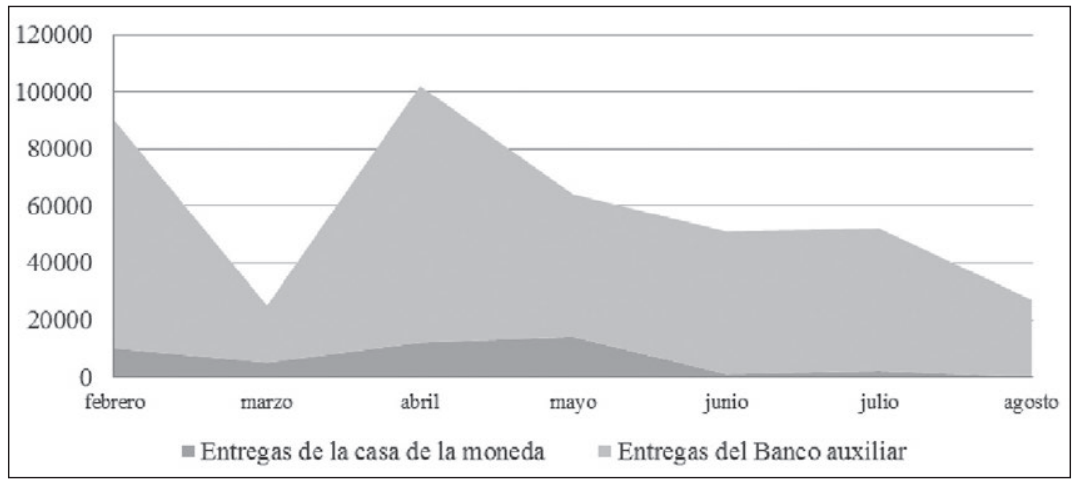

Fuente: Colección documental de la Independencia del Perú (nota 26), pp. 121-232.

32 Ibidem, p. 114.

33 Ibidem, p. 109. 
En definitiva, sin base metálica, a falta de condiciones objetivas, operaciones fraudulentas y extraordinaria emisión, en el mes de julio de 1822, comienza el debate interno en torno a la suspensión del modelo monetario de papel-moneda. El sistema, a pesar de sus numerosos inconvenientes, errores y futuras disfunciones, había logrado, mediante la ampliación de la base monetaria, mantener en pié a un precario Gobierno acorralado por unos gastos militares muy superiores a los inicialmente planificados. De esta forma, el final de la experiencia fiduciaria del Protectorado compromete directamente la vigencia del pretendido Estado al que representaba. Una junta extraordinaria, encargada de estudiar el modo por el cual se procedería a extinguir el papel-moneda en circulación y redefiniría las funciones del banco auxiliar, dictamina sobre el caso a menos de un mes de la salida de San Martín del Perú tras dos días de intensos debates, como así se representa en la siguiente cita:

" $1^{\circ}$. A fines del presente mes de agosto los comerciantes comisionados para la extinción del papel-moneda presentarán en el banco de su giro, 140 mil pesos consolidados en billetes de valor de 2 y 4 reales, ó el dinero efectivos para verificarlo a la mayor brevedad, por ser este el que corre en más cantidad, y que más gravan al pueblo menesteroso.

$2^{\circ}$. Los comisionados serán reintegrados de sus desembolsos con los derechos de aduana que adeuden al término de tres meses contados desde el día de la consolidación.

$3^{\circ}$. Para acelerarla en lo posible, se expenderá en la renta de Tabacos cuanto quiera comprar el público, por solo el referido papel, y sin necesidad de erogación pecuniaria.

$4^{\circ}$. El banco según se le tiene ordenado no circulará absolutamente más papel, bajo de ningún pretexto, y el que se recibiese en la Tesorería del Estado se le devolverá para que cese su cambio.

$5^{\circ}$. Si el gobierno encontrare otros recursos que poder emplear en este objeto, lo ejecutará inmediatamente que se verifique para que a la mayor brevedad posible se extinga en su totalidad el papel-moneda. Entre tanto los pequeños restos que vayan quedando en el círculo deberán ser puntualmente recibidos en todo género de contratos conforme a la ley establecida de pagarse la mitad en papel, y la otra en moneda.

Publíquese en gaceta extraordinaria, y comuníquese por el ministerio de Hacienda a quienes corresponda. Dado en el palacio del supremo gobierno en Lima a 13 de agosto de 1822. - Firmado. - Trujillo. - De orden de S.E. - Hipólito Unanue". ${ }^{34}$

\footnotetext{
${ }^{34}$ Ibidem, pp. 117-118.
} 


\section{Las iniciativas monetarias de La SERna}

El Gobierno de La Serna mantiene un perfil bajo en cuanto a las iniciativas monetarias y financieras durante la primera fase de la guerra. Esperando una resolución relativamente rápida del conflicto, coincidiendo, aunque por motivos opuestos, con las tesis defendidas por los colaboradores militares de San Martín, despliega una labor fiscal y monetaria conservadora. El peso de la guerra, desde la administración cuzqueña, descansa sobre una tradicional gestión, en este caso eficiente, de recursos ordinarios, como así lo atestiguan los escasos datos procedentes del "Libro Manual de las Cajas Reales". ${ }^{35}$ Asimismo hay que contar con los fondos procedentes de la Casa de la Moneda de Lima sustraídos antes de la salida de La Serna de la ciudad.

Sin embargo, la crisis por la que atravesaba el país se intensificó progresivamente a lo largo de 1822. El estado de guerra fue reduciendo paulatinamente la actividad económica y a su vez la capacidad tributaria como así se demuestra en los datos relacionados con el principal objeto de contribución ordinaria, la conocida "Única Contribución", que en ningún momento del ejercicio de 1823 pudo ser recaudada completamente alcanzándose techos de ingresos efectivos progresivamente menores según avanzaba el citado ejercicio fiscal. La práctica totalidad de los subdelegados de los Partidos de la Intendencia tienen crecientes dificultades a la hora de cumplir con el cobro de impuestos estipulados en los presupuestos del Gobierno. A esta precaria situación hay que añadir que a finales de 1823 la Real Hacienda del Cuzco arrastra una deuda de 54.102 pesos y $21 / 2$ reales, por empréstitos hechos al fisco por el vecindario de la Intendencia en 1816-1817. Por todo ello, esta prudente y contenida política fiscal se corrige a partir de 1823, haciendo uso de diversos instrumentos fiscales

${ }^{35}$ Como se señala en la Colección Documental de la Independencia del Perú (nota 26), tomo XXII: Documentación Oficial Española, vol. 3: Gobierno Virreinal del Cuzco, Estado Económico, pp. 25-26. "En cuanto al aspecto económico de la administración de La Serna cabe destacar la falta de un documento fundamental, el "Libro manual de las Cajas Nacionales" correspondiente al año de 1822, libro extraviado en la Tesorería Fiscal que no es recepcionado en el Archivo Histórico del Cuzco, como sí ocurre con los correspondientes a los ejercicios de 1823 y 1824. Además, es en 1822 cuando las Cajas Reales del Cuzco se convierten en Cajas Nacionales". De tal forma que para poder analizar el ejercicio de 1822, únicamente disponemos de la liquidación y resumen de 1822 que aparece al inicio del Libro Manual de 1823. 
extraordinarios entre los que destacan préstamos forzosos, contribución de predios rústicos, cupos al comercio y donativos y préstamos voluntarios.

En cuanto a la primera figura, préstamos forzosos, se activa el 31 de enero de 1823 por la suma de 40.000 pesos sobre todas aquellas personas civiles y eclesiásticas cuyas rentas excedían de 2.000 pesos, y los conventos de regulares que objetivamente pudieran hacer frente a dicha carga tributaria. La acotación se realiza el 15 de febrero a cargo de la Diputación Provincial y el Ayuntamiento de Cuzco, quedando establecida de la siguiente forma: 16 individuos del estado eclesiástico, cinco comunidades religiosas, ${ }^{36}$ seis miembros de la Diputación Provincial, 79 personalidades del ayuntamiento y del comercio de la ciudad. ${ }^{37}$ Todos ellos sumaron la cantidad de 17.075 pesos como aporte del cercado de Cuzco, mientras que los demás partidos - distribuidos de la siguiente forma: 63 vecinos del Partido de Quispicanchis, 69 de Urubamba, 49 de Calca, 35 de Chumbivilcas, 50 de Tinta, 32 de Paucartambo, 16 de Aymaraes y 62 de Abancay alcanzaron la cifra de 22.925 pesos. $^{38}$

La siguiente figura, contribución de predios rústicos, es decretada por el virrey el 4 de junio de 1823 por la suma de 50.000 pesos sobre haciendas y tierras de propiedad y de usufructo sin dominio. La acotación por partidos la realiza el intendente Álvarez el 18 de noviembre asignando a Aymaraes $1.599 \$ 2$ rs., Abancay $8.875 \$$ 5 1/2rs., Urubamba 11.034\$ 7 1/2rs., Calca 3.388\$ 7rs., Paucartambo 4.809\$ 6 1/2rs., Tinta 2.797\$, Quispicanchis 8.663\$ 5rs., Chumbivilcas $1.049 \$$ 6rs., Cotabambas $667 \$ 61 \frac{1}{2}$ rs., Paruro, $4.687 \$ 51 / 2$ rs., y Cercado, $3.230 \$ 41 / 2$ rs.; haciendo la suma de todos $50.804 \$ 5$ rs. ${ }^{39}$

${ }^{36}$ Archivo Histórico de Cuzco (en adelante AHC), Libro de correspondencia e informes al Gobierno Intendencia de la capital de Cuzco. Año de 1823, fs. 50, publicado en Colección Documental de la Independencia del Perú, tomo XXII, vol. 3 (nota 35), p. 30.

37 AHC, Libro Manual (nota 35) de 1824, Part. 196 y 317, fs. 32 v., 33 y 52 v.: publicado en Colección Documental de la Independencia del Perú, tomo XXII, vol. 3 (nota 35), p. 27.

38 AHC, Libro de Tomás de Razón para la Contaduría principal de Cuzco que da principio en 14 de enero de 1823, fs. 89-94 v.: publicado en Colección Documental de la Independencia del Perú, tomo XXII, vol. 3 (nota 35), p. 31.

39 Ibidem, fs. 99 v.-100, publicado en Colección Documental de la Independencia del Perú, tomo XXII, vol. 3 (nota 35), p. 32. 
La recaudación, encargada a los subdelegados, no fue cumplida en plazo, y el 20 de febrero de 1824 el ministro tesorero José María Sánchez Chávez insta al intendente de Cuzco que termine la operación de recogida, pendiente todavía de 18.511 pesos y medio real por cuenta del cupo. Todavía en la avanzada fecha de 20 de julio de 1824 quedan partidos, como el de Abancay, que adeudan sumas menores. ${ }^{40}$

La tercera iniciativa extraordinaria, los cupos al comercio, se pone en marcha a través de la circular de 29 de abril de 1823, mediante la cual La Serna se dirige al comercio español de Cuzco para que proporcione al Gobierno 20.000 pesos en empréstito voluntario, tras haber realizado la misma gestión con Arequipa (250.000 pesos), La Paz (160.000 pesos), y Potosí y Chuquisaca (80.000 pesos). El intendente Antonio María Álvarez se encarga de gestar el acuerdo que finalmente se materializa el 12 de mayo, con un préstamo que alcanza la suma de 13.375 pesos que se les satisfará del ramo de Alcabalas. El expediente sigue un sinuoso recorrido de diversos trámites, terminando con una primera entrega de 10.250 pesos el 31 de junio y 10.750 pesos el 18 de noviembre, superando la cantidad fijada inicialmente de 20.000 pesos $^{41}$.

El 20 de febrero de 1824 se decreta un segundo cupo de 20.000 pesos - debido a las serias dificultades económicas - a cargo de los comerciantes de Cuzco. El objetivo es el de cubrir de forma urgente el presupuesto del Ejército del Norte. La cantidad se distribuye entre los individuos que por su giro tengan que pagar derechos de aduanas, a fin de que pasada la razón de la cantidad que a cada uno corresponde pagar, se pase la orden para que se le vaya reintegrando, no pagando sino la mitad de los derechos que vaya adeudando. En definitiva, el préstamo se duplica en el momento de cancelar derechos de aduana por futuras importaciones. El plazo máximo se fija para el 12 de marzo, aunque tiene que ser corregido progresivamente. La exacción se hace extensiva a los individuos del gremio de comerciantes del Cuzco cuyo principal es mayor de 1.000 pesos. Finalmente el cupo es reducido a 15.750 pesos, recurriendo 74 individuos, muchos de los cuales pagan

40 AHC, Libro de Correspondencia e Informes (nota 36), fs. 84 v., 85 y 125, publicado en Colección Documental de la Independencia del Perú, tomo XXII, vol. 3 (nota 35), p. 32.

${ }^{41}$ AHC, Libro Manual (nota 35) de 1823. Part. 944 de 31 de julio de 1823, y 1419 de 18 de noviembre de 1823, fs. 142 v. y 204 v.-205: publicado en Colección Documental de la Independencia del Perú, tomo XXII, vol. 3 (nota 35), p. 33. 
parte del cupo asignado en especie. ${ }^{42}$ Por su parte, la Intendencia de La Paz acaba entregando a la Caja de Cuzco la suma de 61.516 pesos de un cupo inicial de $80.000 \$$, a través de dos entregas en 6 de junio y 15 de julio de $1823 .{ }^{43}$ En cuanto a Potosí, el 22 de diciembre consta la entrada de 12.154 pesos a cargo del comercio y $15.000 \$$ de vecinos ${ }^{44}$. Y finalmente, de Cochabamba el 6 de junio de 18236.000 pesos..$^{45}$ No hay datos relativos a Huamanga, Huancavelica, Tarma, Arequipa y Puno, aunque con respecto a esta última intendencia el contingente ordinario y mensual ascendía a 16.000 pesos.

Por último, la cuarta figura a la que recurre la administración virreinal es el de donativos y préstamos voluntarios. En este caso la capacidad de recaudación es muy limitada y La Serna, en su objetivo de no consumar el deterioro del crédito público devuelve, en gran parte, el dinero prestado a través de estos donativos y préstamos voluntarios. A continuación se señala la relación de los más importantes: 15 de marzo de 1823, Manuel Fernández Coronel, subdelegado de Aymaraes, dona al Ejército realista la cantidad de 467 pesos $51 / 2$ rs. ${ }^{46} 4$ de abril de 1823, Manuel Ranero Caballero entrega 2.000 pesos en las Cajas de Cuzco; ${ }^{47} 11$ de julio de 1823, Francisco Ruiz de Sorsano entrega 1.000 pesos; ${ }^{48} 18$ de noviembre de 1823 , el brigadier Ignacio Landázuri presta 9.000 pesos; ${ }^{49} 22$ de noviembre, el coronel Eulogio Santa Cruz, secretario del Virreinato, cubre la suma de 5.040 pesos; ${ }^{50} 18$ y

42 AHC, Libro de Tomás de Razón, fs. 75 v.-77 y 253-254: publicado en Colección Documental de la Independencia del Perú, tomo XXII, vol. 3 (nota 35), p. 34.

${ }^{43}$ AHC, Libro Manual (nota 35) de 1823, Part. 664 y 870: publicado en Colección Documental de la Independencia del Perú, tomo XXII, vol. 3 (nota 35), p. 35.

${ }^{44}$ AHC, Libro Manual (nota 35) de 1823, Part. 1581 y 870: publicado en Colección Documental de la Independencia del Perú, tomo XXII, vol. 3 (nota 35), p. 35.

45 AHC, Libro Manual (nota 35) de 1823, Part. 665: publicado en Colección Documental de la Independencia del Perú, tomo XXII, vol. 3 (nota 35), p. 35.

46 AHC, Libro Manual (nota 35) de 1823, Part. 263, fs. 44 y 44 v.: publicado en Colección Documental de la Independencia del Perú, tomo XXII, vol. 3 (nota 35), p. 35 .

47 AHC, Libro Manual (nota 35) de 1823, Part. 349, fs. 57: publicado en Colección Documental de la Independencia del Perú, tomo XXII, vol. 3 (nota 35), p. 36.

48 AHC, Libro Manual (nota 35) de 1823, Part. 852, fs. 129: publicado en Colección Documental de la Independencia del Perú, tomo XXII, vol. 3 (nota 35), p. 36.

49 AHC, Libro Manual (nota 35) de 1823, Part. 1420, fs. 205: publicado en Colección Documental de la Independencia del Perú, tomo XXII, vol. 3 (nota 35), p. 36.

${ }^{50}$ AHC, Libro Manual (nota 35) de 1823, Part. 1440, fs. 208: publicado en Colección Documental de la Independencia del Perú, tomo XXII, vol. 3 (nota 35), p. 36. 
24 de diciembre, Lucas de la Cotera, comerciante de Arequipa, dona 8.203 y 1.050 pesos respectivamente, además de otras cantidades menores. ${ }^{51}$

Sin embargo, a finales de 1823, los ingresos ordinarios y las contribuciones extraordinarias no son suficientes para mantener las exigencias de una Hacienda acuciada por los gastos bélicos, como se detalla en los cuadros siguientes:

\section{CuAdro 1: Resumen DE CARGO DATA Y EXISTENCIAS CON GOTEJO DEL LIBRO MAYOR, 1823}

\begin{tabular}{l|r}
\hline Existencias en dinero y buenas cuentas & $\mathbf{1 5 1 . 4 8 5 , 3}$ \\
\hline En especies reconocidas & $13.102,7$ \\
En deudas por cobrar & $95.053,7$ \\
Total fondo & $259.642,2$ \\
Créditos pasivos liquidados & $807.042,1$ \\
Alcance contra el fondo a 31 de diciembre de 1823 & $547.399,7$ \\
\hline
\end{tabular}

Fuente: Colección Documental de la Independencia del Perú, tomo XXII: Documentación oficial española, vol. 3: Gobierno Virreinal del Cuzco, p. 29.

\section{CuAdro 2: Resumen de CARGo DATA Y EXISTENCIAS CON GOTEJO DEL LIBRO MAYOR, 1824}

\begin{tabular}{l|r}
\hline Existencias en dinero y buenas cuentas & $\mathbf{5 . 6 6 2 . 7}+\mathbf{2 7 . 5 7 0}$ \\
\hline En especies reconocidas & $13.161,3$ \\
En deudas por cobrar & 72.582 \\
Total fondo & $118.976,3$ \\
Créditos pasivos liquidados & $790.437,1$ \\
Alcance contra el fondo a 31 de diciembre de 1823 & $671.460,6$ \\
\hline
\end{tabular}

Fuente: Colección Documental de la Independencia del Perú, tomo XXII: Documentación oficial española, vol. 3: Gobierno Virreinal del Cuzco, p. 29.

51 AHC, Libro Manual (nota 35) de 1823, Part. 1449, 1471, 1502, 1572, fs. 209, 212, 216 v., 224 v.: publicado en Colección Documental de la Independencia del Perú, tomo XXII, vol. 3 (nota 35), p. 36. 
Esta situación abre uno de los episodios más sorprendentes e interesantes, desde una perspectiva monetaria, de la guerra de Independencia del Perú: la evacuación, el traslado y establecimiento de la Casa de la Moneda de Lima en la ciudad de Cuzco.

\section{La Casa de la Moneda de Cuzco}

En la salida del general Canterac de la ciudad de Lima en julio de 1823, La Serna ordena trasladar la maquinaria de la Casa de Moneda hasta Cuzco con el doble objetivo de, por una parte, privar a los independentistas de este extraordinario instrumento y, por otra, poder disponer de él a favor de su Gobierno. El 17 de julio Canterac informa desde Lurín sobre este particular al virrey detallando la extracción de toda la maquinaria, dependientes y operarios de la citada institución. El teniente coronel Manuel Vigil es el encargado de llevar a cabo la operación de transporte desde Huancayo hasta Cuzco mientras la Real Hacienda concluye todos los preparativos necesarios para su final instalación en la sede del Virreinato. ${ }^{52}$ La orden de traslado y plantificación se resuelve en diciembre de 1823. El Convento y Hospital de San Juan de Dios ${ }^{53}$ es el local elegido para la ubicación de la futura Casa de la Moneda de Cuzco (el estado de la antigua Callana de las Cajas Reales desaconsejan esta ubicación natural), actuando José María de Lara, asesor general del Virreinato - sobre la base de su experiencia como ensayador propietario de las Cajas de Potosí - como consejero en la cuestión de la instalación de la Casa de la Moneda. ${ }^{54}$ A su vez, La Serna hace llamar, con fecha 28 de noviembre de 1823, a Cuzco a Manuel Solares, tesorero de la Casa de la Moneda de Potosí, con el objetivo de dirigir los trabajos de instalación de la casa cuzqueña. Los gastos de la obra entre el 26 de enero y el 26 de junio de 1824 ascienden a 15.800 pesos $^{55}$ debido a las dificul-

${ }^{52}$ AHC, Libro Manual (nota 35) de 1824, Part. 53, 153 y 408: publicado en Colección Documental de la Independencia del Perú, tomo XXII, vol. 3 (nota 35), p. 36.

${ }^{53}$ AHC, Libro de Correspondencia e Informes (nota 36), fs. 81, n 24, publicado en Colección Documental de la Independencia del Perú, tomo XXII, vol. 3 (nota 35), p. 37.

${ }_{54}$ AHC, Oficio al Gobernador Intendente de Potosí de 28 de noviembre de 1823. Libro de Tomás de Razón, fs. 129: publicado en Colección Documental de la Independencia del Perú, tomo XXII, vol. 3 (nota 35), p. 38.

${ }_{55}$ AHC, Libro Manual (nota 35) de 1824, Part. 127, 145, 176, 214, 257, 280, 316, 335, 347, 377, 402, 426, 491, 504, 518, 558, 602 y 770: publicado en Colección Documental de la Independencia del Perú, tomo XXII, vol. 3 (nota 35), p. 38. 
tades que entraña el adaptar un establecimiento al complejo sistema de producción de una Casa de Moneda, además de las inversiones en infraestructuras que implican el proveer al centro del agua suficiente para proporcionar la fuerza motriz capaz de mover la pesada maquinaria.

El personal de la Casa de la Moneda está compuesto por un grupo de profesionales con larga experiencia en la ceca limeña, entre los que destacan: el superintendente Pablo Terón, el guarda cuños Fernando Barea, el contador de monedas Domingo Arriaga y el oficial de $2^{\mathrm{a}} \mathrm{de}$ contaduría Manuel Urrutia. A este equipo inicial se sumarán en julio de 1824 como fiel Martín Casuso y como ensayador Tomás Paniso, y procedentes de Potosí el contador Juan Bautista de la Rosa y el ensayador Gregorio Carril. ${ }^{56}$

La Serna, en paralelo a los trabajos de instalación de la Casa de Moneda, mediante decretos de 6 de marzo y 5 de junio, ${ }^{57}$ establece el rescate de plata por las Tesorerías a fin de asegurar la dotación de materia prima para una estable y constante amonedación. Por una parte, en el Banco de San Carlos de Potosí, así como en todas las Tesorerías, se fijan las siguientes tarifas de compra de metales en pasta que los mineros llevaran a vender:

\section{CUADRO 3: TARIFAS DE COMPRA}

\begin{tabular}{l|l}
\hline \multicolumn{1}{c|}{ Tipología } & \\
\hline Piñas beneficiadas cuyo peso exceda de 30 marcos & 7 pesos 2 reales \\
Los menores hasta 10 & 7 pesos 1 real \\
En piñones, piezas menudas y planchas & 6 pesos 6 reales \\
Chafalonía y vajilla & 6 pesos \\
Plancha fundida & No se admite \\
\hline
\end{tabular}

Fuente: Colección Documental de la Independencia del Perú, tomo XXII: Documentación oficial española, vol. 3: Gobierno Virreinal del Cuzco, p. 39.

Por otra parte, se dispone que las barras que se fundan en las Cajas de Oruro y La Paz se remitan con guía a Potosí, mientras que las que se

${ }^{56}$ AHC, Libro Manual (nota 35) de 1824, Part. 191, 215, 312, 466 y 547: publicado en Colección Documental de la Independencia del Perú, tomo XXII, vol. 3 (nota 35), p. 39.

57 Decretos de La Serna recogidos de la Colección "El Depositario". BICUC, Vol. 759-30, publicado en Colección Documental de la Independencia del Perú, tomo XXII, vol. 3 (nota 35), pp. 129-134. 
procesan en Puno, Arequipa, Tarma, Huamanga, Tacna y Huancavelica sean remitidas a las Casas de la Moneda de Cuzco. Lo mismo se decreta con el oro, debiendo ser éste quintado y marcado previamente en la Caja correspondiente antes de ser remitido a las Casas de la Moneda.

Destaca como en medio de unas críticas circunstancias de estado de guerra se logra legislar sobre la cuestión monetaria con relativa aspiración reformista con el objetivo de establecer la regularidad en la circulación de numerario, ofreciendo unas elevadas tarifas de compra a mineros y poseedores de plata. El establecimiento cumple un importantísimo papel, según consta en los registros de la Tesorería General, realizando importantes entregas de dinero al Gobierno en momentos económicos críticos, y manteniendo a su vez una eficiente y novedosa gestión de la institución monetaria.

\section{CONCLUSIÓN}

Durante la década de 1820, tanto la Península como los antiguos territorios de Ultramar, ahora como naciones incipientes, comparten un mismo problema: la escasez de numerario. El obstinado mantenimiento, por parte de la Corona española, de una política monetaria tradicional más preocupada por el orden fiscal que por alcanzar objetivos modernos conduce a ambas orillas del Atlántico a la necesidad de un planteamiento reformista en la esfera monetaria que permita, por una parte, salir del marasmo monetario al que ha conducido el viejo sistema y, por otro, crear unas nuevas condiciones monetarias y financieras que permitan a las economías desenvolverse de forma eficaz en un marco internacional que se regula mediante relaciones económicas modernas.

España pretende salir de la encrucijada a través de la puesta en marcha de una amplia reforma monetaria, aun con importantes limitaciones, impulsada por el Trienio Liberal, que pretende transformar profundamente las Casas de la Moneda. En el caso de Perú, este momento coincide con la guerra de Independencia y también contribuye, a pesar de la situación excepcional, a la búsqueda de soluciones que permitan salir de la situación de postración monetaria. Cada cual a su manera, desde el bando patriótico desplegando un ambicioso proyecto de implantación del sistema fiduciario que le permitiera resolver 
su ecuación de máquinas sin plata; y desde el bando realista, una vez sorteada la limitación de plata sin máquinas, articulando una agresiva política de atracción de pastas mediante el establecimiento de elevadas tarifas de compra que estimulasen los deprimidos niveles de acuñación. En la Península, la pervivencia del sistema absolutista tras la invasión de los Cien Mil Hijos de San Luis cerrará cualquier vía reformista. En el caso de Perú, está demasiado cerca del epicentro de la convulsión para beneficiarse de la acelerada transformación. 
Brought to you by | Universidad de la Rioja Authenticated Download Date | 1/22/18 1:10 PM 